\title{
Effect of cariporide on ram sperm pH regulation and motility: possible role of NHE1
}

\author{
Stefania Muzzachi ${ }^{1}$, Lorenzo Guerra ${ }^{1}$, Nicola Antonio Martino ${ }^{1,2}$, Maria Favia ${ }^{1}$, \\ Giuseppe Punzi ${ }^{1}$, Fabio Silvestre ${ }^{3}$, Antonio Ciro Guaricci ${ }^{3}$, Maria Teresa Roscino ${ }^{3}$, \\ Ciro Leonardo Pierri ${ }^{1}$, Maria Elena Dell'Aquila ${ }^{1}$, Valeria Casavola', \\ Giovanni Michele Lacalandra ${ }^{3}$ and Elena Ciani ${ }^{1}$ \\ ${ }^{1}$ Department of Biosciences, Biotechnologies and Biopharmaceutics, University of Bari 'Aldo Moro', Bari, Italy, \\ ${ }^{2}$ Istituto Zooprofilattico Sperimentale della Puglia e della Basilicata, Foggia, Italy and ${ }^{3}$ Section of Veterinary Clinics \\ and Animal Productions, Department of Emergency and Organ Transplantation, University of Bari 'Aldo Moro', \\ Valenzano, Bari, Italy
}

Correspondence should be addressed to L Guerra; Email: lorenzo.guerra1@uniba.it

\begin{abstract}
Sperm motility, a feature essential for in vivo fertilization, is influenced by intracellular $\mathrm{pH}\left(\mathrm{pH}_{\mathrm{i}}\right)$ homeostasis. Several mechanisms are involved in $\mathrm{pH}_{\mathrm{i}}$ regulation, among which sodium-hydrogen exchangers (NHEs), a family of integral transmembrane proteins that catalyze the exchange of $\mathrm{Na}^{+}$for $\mathrm{H}^{+}$across lipid bilayers. A preliminary characterization of NHE activity and kinetic parameters, followed by analysis of the expression and localization of the protein in ram spermatozoa was performed. NHE activity showed an apparent $K_{\mathrm{m}}$ for external $\mathrm{Na}^{+}$of $\mathbf{1 7 . 6 1} \mathrm{mM}$. Immunoblotting revealed a molecular mass of $85 \mathrm{kDa}$. Immunolocalization pattern showed some species-specific aspects, such as positive labeling at the equatorial region of the sperm head. Cariporide, a selective NHE1 inhibitor, significantly reduced $\mathrm{pH}_{\mathrm{i}}$ recovery $(85 \%)$. Similarly, exposure to cariporide significantly inhibited different motility parameters, including those related to sperm capacitation. In vitro fertilization (IVF) was not affected by cariporide, possibly due to the non-dramatic, although significant, drop in motility and velocity parameters or due to prolonged exposure during IVF, which may have caused progressive loss of its inhibitory effect. In conclusion, this is the first study documenting, in a large animal model (sheep) of well-known translational relevance, a direct functional role of NHE on sperm $\mathrm{pH}_{\mathrm{i}}$ and motility. The postulated specificity of cariporide toward isoform 1 of the $\mathrm{Na}^{+} / \mathrm{H}^{+}$exchanger seems to suggest that $\mathrm{NHE} 1$ may contribute to the observed effects on sperm cell functionality.

Reproduction (2018) 155 433-445
\end{abstract}

\section{Introduction}

At the end of its differentiation program, the sperm cell must acquire motility in order to be able to accomplish its mission, i.e. oocyte fertilization. Sperm motility, defined as a propagation of transverse waves along the flagellum in a proximal-distal direction, producing an impulse that pushes the spermatozoon in a straightforward manner through the male and the female reproductive system (Paoli et al. 2011), is a fundamental characteristic of sperm function and provides a reliable diagnostic and prognostic measure for male fertility. Sperm motility is achieved when the sperm cell has a fully developed and functionally active flagellum, or axoneme, and when the cell is capable of producing energy to fuel the movements. It is acquired in the male reproductive system, during the journey through the epididymis, where is called 'primary or activated motility' characterized by symmetrical tail movements with low amplitude. Subsequently, it pursues through the female reproductive system, from the vagina and through the uterus to the fallopian tube, where it changes in 'hyperactivated motility' characterized by high amplitude and asymmetric flagellar bends occurring, in particular, when sperm cells reach the cumulus-oocyte complex (COC) in the ampullary tract (reviewed by Freitas et al. 2017).

As sperm is virtually devoid of transcription and translation due to highly condensed DNA and lack of endoplasmic reticulum (Baldi et al. 2002), activation or inhibition of specific signaling pathways play the most important roles in motility regulation. Indeed, the interaction between sperm and the environment created by the epididymis and the female reproductive tract are essential to trigger sperm motility. In this regard, the various processes that take place, at the sperm cell level, along the male and the female reproductive tract of mammals, are affected by $\mathrm{pH}$ levels in the several 
luminal fluids (Martins et al. 2014, Sakkas et al. 2015, Ng et al. 2017) and disturbances of acid-base homeostasis have been associated with infertility or subfertility (reviewed by Martins et al. 2014). Thus, an interactive link exists between the ability of the sperm cell to maintain its correct intracellular $\mathrm{pH}$ and sperm motility, but this field of investigation is not yet extensively explored. It is known from the literature that two main categories of transmembrane proteins are involved in cell $\mathrm{pH}$ regulation, bicarbonate and proton carriers, respectively (Martins et al. 2014). The latter include a family of proteins, commonly termed sodium-hydrogen exchangers (NHEs), involved in the electroneutral exchange of intracellular $\mathrm{H}^{+}$with extracellular $\mathrm{Na}^{+}$according to the concentration gradient across the membrane (Freitas et al. 2017, Pereira et al. 2017). These proteins are widely expressed in several cell systems and are highly effective in $\mathrm{pH}_{\mathrm{i}}$ regulation. In sperm cells, early studies on activity and role of sodium-hydrogen exchangers had been carried out in the sea urchin (Lee \& Garbers 1986). More recently, NHEs have been shown to induce a raise of the intracellular $\mathrm{pH}$, a mechanism which in turn activates CatSper, a cation channel of sperm cells that enables the entry of calcium, thus influencing glycolysis and the axoneme activity (Freitas et al. 2017, Pereira et al. 2017). Four isoforms (isoenzymes) of NHE have been identified so far on the sperm cell plasma membrane, namely NHE1, NHE5, mtsNHE (testis-specific NHE) and NHE10. The latter is also known as the sperm-specific NHE isoform (sNHE) as it is exclusively expressed in spermatozoa (Martins et al. 2014, Zhang et al. 2017) and has been already shown, similarly to mtsNHE, to play a role in affecting sperm motility (Wang et al. 2003, 2007, Liu et al. 2010, Zhang et al. 2017). Decreased motility, responsible for selective male infertility, and associated to sperm morpho-functional abnormalities, was also described in mice null for the organellar NHE8 isoform (Oberheide et al. 2017). No direct evidence for the involvement of the plasma membrane NHE1 and NHE5 isoforms in sperm motility has been provided so far. Between these two isoforms, NHE1 represents a better selection candidate for playing a role in the regulation of sperm function, as it is recognized as one of the most important systems involved in $\mathrm{pH}$ regulation in a wide variety of cell systems and is upregulated in different types of pathological conditions (Donowitz et al. 2013, Padan \& Landau 2016). In addition, targeted disruption of the NHE1 locus in mouse was found to be associated with significant lifespan reduction in the offspring and variable effects on fertility according to the used breeding schemes either in homozygosity or heterozygosity (Bell et al. 1999). Furthermore, an indirect involvement of NHE1 in rat sperm motility was previously suggested by Woo et al. (2002) through the use of ouabain, an inhibitor of the $\mathrm{Na}^{+} /$ $\mathrm{K}^{+}$-ATPase, that impairs the driving force for sodium. However, the adopted approach does not provide a definitive proof for the specific involvement of NHE1, as all $\mathrm{Na}^{+} / \mathrm{H}^{+}$exchanger isoforms depend on the $\mathrm{Na}^{+}$ gradient. To our knowledge, no studies have been reported to date of a direct involvement of NHE1 in sperm motility using its specific inhibitors.

In light of these considerations, and given the recent increased attention to NHE1-specific inhibitors, due to their use in the regulation of different cell functions with therapeutic purposes (Mihaila 2015), the aim of this study was to perform, for the first time, an evaluation of the effects of cariporide (HOE642), a documented selective inhibitor of NHE1, on sperm intracellular $\mathrm{pH}$, motility and fertilizing ability. The study was performed on the ovine species as previous evidences supported it as an optimal animal model for translational studies in human reproductive physiology (Sutovsky et al. 1996).

\section{Materials and methods}

\section{Ethics statement}

Experiments were carried out at University of Bari, Southern Italy $\left(42^{\circ}\right.$ north parallel) during reproductive seasons (September to November) 2014-2016. For animal handling and semen collection, the Principles for the Care and Use of Research Animals, promulgated by the European Community, were followed. Semen collection was carried out with the rams owners' consent, as part of the routine activities at the Section of Veterinary Clinics and Animal Production, Department of Emergency and Organ Transplantation, which is a recognized center for livestock semen collection and storage, authorized by the Apulian Regional Authority (n. 311/ICA 29/11/2004). As such, no specific approval for this study was required at the Animal Research Ethical Committee ('Comitato Etico per la sperimentazione animale', CESA) of University of Bari.

\section{Semen collection}

Fresh ejaculates where collected from three rams with proven general and reproductive health by using an artificial vagina. The rams were kept under standard housing and feeding conditions at the Teaching Veterinary Hospital of the University of Bari, Italy. After measuring volume, density and coarse motility under light microscopy (80-90\%), semen was diluted 1:10 with a non-capacitating medium in order to avoid interference with bicarbonate-dependent $\mathrm{pH}$ regulatory mechanisms. A modified bicarbonate-free Sperm Analysis Medium (Cox et al. 2006), namely $\mathrm{NaCl}$ medium $(150 \mathrm{mM} \mathrm{NaCl}, 5 \mathrm{mM} \mathrm{KCl}, 2 \mathrm{mM} \mathrm{CaCl}, 1 \mathrm{mM} \mathrm{MgCl}, 10 \mathrm{mM}$ Glucose, $10 \mathrm{mM}$ HEPES, pH 7.4 with $\mathrm{NaOH}$ ), was used. Motile spermatozoa were separated from non-motile ones and seminal plasma by the swim-up technique. Briefly, $100 \mu \mathrm{L}$ of semen were incubated with $1 \mathrm{~mL}$ of $\mathrm{NaCl}$ medium at $37^{\circ} \mathrm{C}$ for $1 \mathrm{~h}$ in a humidified incubator. After incubation, motile 
spermatozoa that were present into the supernatant were collected and used for subsequent analyses.

\section{Western blot}

Spermatozoa $\left(21 \times 10^{6}\right)$ were centrifuged at $16,000 \mathrm{~g}$ for $5 \mathrm{~min}$, homogenized in lysis buffer $(110 \mathrm{mM} \mathrm{NaCl}, 50 \mathrm{mM}$ TRIS, 0.5\% (v/v) Triton X-100, 0.5\% (v/v) Igepal CA-630, pH 8 added with $0.2 \%(\mathrm{v} / \mathrm{v})$ protease inhibitor mixture SigmaAldrich P8340), sonicated for $10 \mathrm{~s}$ and placed overnight at $-80^{\circ} \mathrm{C}$. Then, samples were heated at $37^{\circ} \mathrm{C}$ for $30 \mathrm{~min}$ and centrifuged at $16,000 \mathrm{~g}$ for $10 \mathrm{~min}$. Supernatant protein concentration was measured by the method of Bradford (1976). Ghosts preparations were obtained from fresh ram blood. Approximately, $5 \mathrm{~mL}$ of ram blood was diluted in $20 \mathrm{~mL}$ of medium $(120 \mathrm{mM} \mathrm{NaCl}, 10 \mathrm{mM}$ EDTA, $5 \mathrm{mM}$ sodium citrate and $5 \mathrm{mM}$ Tris- $\mathrm{HCl}, \mathrm{pH} 7.4)$ and centrifuged at $1500 \mathrm{~g}$ for $10 \mathrm{~min}$. The pellet was washed twice by gentle resuspension in $20 \mathrm{~mL}$ of $\mathrm{PBS}, \mathrm{pH} \mathrm{7.4}$, and subsequent centrifugation at $1500 \mathrm{~g}$ for $15 \mathrm{~min}$, and then it was resuspended and incubated in $5 \mathrm{mM}$ phosphate buffer. After $1 \mathrm{~h}$ of incubation, the sample was centrifuged at 13,000 $\mathrm{g}$ for $30 \mathrm{~min}$ at $4{ }^{\circ} \mathrm{C}$ and the pellet was resuspended in $5 \mathrm{mM}$ phosphate buffer and further centrifuged at 13,000 $\mathrm{g}$ for $30 \mathrm{~min}$ at $4^{\circ} \mathrm{C}$. The final pellet was resuspended in distilled water. Protein concentration was measured as mentioned earlier. For both sperm proteins and ghosts, a $30 \mu \mathrm{g}$ aliquot was diluted in Laemmli buffer, heated at $100^{\circ} \mathrm{C}$ for $5 \mathrm{~min}$ and separated by $9 \%$ (v/v) Tris/HCI SDS/PAGE gel electrophoresis under reducing conditions. The separated proteins were transferred to Immobilon P (Millipore) for immunoblotting (Favia et al. 2014). The used antibodies were a monoclonal anti-NHE1 antibody (1:400 dilution), which specifically binds the amino-terminal domain (ab58304; Abcam) and an anti-NHE1 polyclonal antibody (1:400 dilution) against the C-terminus epitope (AB3081; Chemicon by Merck Millipore). After washing, blots were incubated with antimouse or anti-rabbit secondary antibodies conjugated to peroxidase (1:2000 dilution). Immunocomplexes were detected with the ECL plus reagent (GE Healthcare Life Sciences).

\section{Immunofluorescence}

Suspensions of $5 \times 10^{5}$ spermatozoa were seeded on round glass coverslips treated with polylysine. Then, sperm cells were fixed in $4 \%(\mathrm{v} / \mathrm{v})$ paraformaldehyde for $20 \mathrm{~min}$ and permeabilized using $0.1 \%(\mathrm{v} / \mathrm{v})$ Triton $\mathrm{X}-100$ in PBS for $10 \mathrm{~min}$, blocked using $0.1 \%(\mathrm{w} / \mathrm{v})$ gelatin in PBS for $10 \mathrm{~min}$. Afterward, spermatozoa were incubated for $2 \mathrm{~h}$ with primary antibodies, the monoclonal anti-NHE1 (1:200 dilution) or the polyclonal anti-NHE1 (1:200 dilution) previously adopted in the Western blot analysis. Spermatozoa were subsequently incubated with goat anti-mouse or anti-rabbit IgG secondary antibodies conjugated to Alexa Fluor 488 (1:1000 dilution) for $1 \mathrm{~h}$. Coverslips were then mounted onto slides using ProLong Gold Antifade Reagent with DAPI (Invitrogen) and examined with Leica DMRXA microscope. Specimens were viewed through a $100 \times$ oil immersion objective and images were acquired by NIKON digital camera DXM1200.

\section{Intracellular $\mathrm{pH}$ spectrofluorimetric analysis}

Spermatozoa were incubated with $5 \mu \mathrm{M}$ BCECF-AM (2',7'-Bis-(2-Carboxyethyl)-5-(and-6)-Carboxyfluorescein, Acetoxymethyl Ester) for $30 \mathrm{~min}$ at room temperature under constant agitation in $\mathrm{NaCl}$ medium and then centrifuged at $500 \mathrm{~g}$ for $5 \mathrm{~min}$. The pellet was resuspended in $\mathrm{NaCl}$ medium, added with $40 \mathrm{mM} \mathrm{NH}_{4} \mathrm{Cl}$ and incubated for 10 min. In the medium, $\mathrm{NH}_{4} \mathrm{Cl}$ dissociates to $\mathrm{NH}_{3}$, which readily crosses the cell membrane and, due to binding to $\mathrm{H}^{+}$, leads to a rapid intracellular alkalinization. The suspension was then centrifuged at $500 \mathrm{~g}$ for $5 \mathrm{~min}$, and the pellet was incubated for $15 \mathrm{~min}$ in a $\mathrm{Na}^{+}$-free medium $(150 \mathrm{mM} \mathrm{TMACl}$ (tetramethylammonium chloride), $5 \mathrm{mM} \mathrm{KCl}, 2 \mathrm{mM} \mathrm{CaCl}$, $1 \mathrm{mM} \mathrm{MgCl}$, $10 \mathrm{mM}$ Glucose, $10 \mathrm{mM}$ HEPES, pH 7.4 adjusted with $\mathrm{KOH}$ ), thus removing external $\mathrm{NH}_{4} \mathrm{Cl}$ and leading to intracellular acidification via the reverse $\mathrm{NH}_{3}$ extrusion process. After incubation, sperm cells were centrifuged at $500 \mathrm{~g}$ for $5 \mathrm{~min}$ and the pellet was resuspended in $\mathrm{Na}^{+}$-free medium. To evaluate NHE activity, spermatozoa $\left(10 \times 10^{6}\right)$ were added in a quartz cuvette containing the $\mathrm{NaCl}$ medium at different $\mathrm{Na}^{+}$concentrations $(15,30,75,150 \mathrm{mM})$ and placed into the spectrofluorometer (Cary Eclipse Varian). The fluorescence was measured at excitation wavelengths of 450 and $500 \mathrm{~nm}$ and emission wavelength of $535 \mathrm{~nm}$. Intracellular $\mathrm{pH}$ was estimated from the ratio of BCECF fluorescence calibrated by using the $\mathrm{K}^{+}$ nigericin method (Thomas et al. 1979, Montrose et al. 1987). Briefly, for the calibration curve, sperm cells were incubated with $5 \mu \mathrm{M}$ BCECF-AM and $5 \mu \mathrm{M}$ nigericin in a $\mathrm{KCl}$ medium $\left(110 \mathrm{mM} \mathrm{KCl}, 20 \mathrm{mM} \mathrm{NaCl}, 1 \mathrm{mM} \mathrm{CaCl}, 1 \mathrm{mM} \mathrm{MgSO}{ }_{4}\right.$, $1 \mathrm{mM} \mathrm{KH}_{2} \mathrm{PO}_{4}, 18 \mathrm{mM}$ D-Glucose, $20 \mathrm{mM}$ HEPES, $\mathrm{pH}$ 7.4) for $30 \mathrm{~min}$. After incubation, sperm cells were centrifuged at $500 \mathrm{~g}$ for $5 \mathrm{~min}$ and the pellet was resuspended in the $\mathrm{KCl}$ medium added with nigericin; the fluorescence was then measured in the $\mathrm{KCl}$ medium at different $\mathrm{pH}$ values $(6,6.5,7$ and 7.5). To estimate the values for the kinetic parameters $V_{\max }$ and $K_{\mathrm{m}}$, we adopted the Woolf-Augustinsson-Hofstee equation, a linearized form of the Michaelis-Menten equation that can be advantageously used to plot $(V /[S])$ against $V$, where $V$ represents $(\Delta \mathrm{pH} / \mathrm{min})$ and $S$ represents the substrate (in our case, the extracellular $\mathrm{Na}^{+}$concentration). In the obtained plot, the $y$ intercept represents $V_{\max }$ the $x$ intercept represents $V_{\max } / K_{\mathrm{m}}$ and the slope represents $-K_{\mathrm{m}}$. Data were expressed as mean \pm standard error (S.E.). Statistical comparisons were made using the unpaired Student's $t$-test, adopting a significance threshold of $P<0.05$.

\section{NHE1 inhibitors}

An extensive literature review on specific NHE1 inhibition studies provided evidence on the common use of dimethylamiloride (DMA) and cariporide (HOE642), respectively, an amiloride-derivative and a benzoylguanidine derivative. For both inhibitors, concentration ranges between nanomolar to micromolar are described. As we worked on an animal species for which, to the best of our knowledge, 
no previous studies on NHE inhibition had been published in any cell system, for both inhibitors, we adopted micromolar concentration values well above the reported DMA and cariporide $\mathrm{IC}_{50}$ for $\mathrm{NHE1}$ and below the cariporide $\mathrm{IC}_{50}$ for NHE5 (Masereel et al. 2003).

\section{Protein sequence alignment, 3D modeling and docking analyses}

NHE1, NHE5, NHE8 and NHE10 orthologous sequences were sampled from the refseq database by using blastp and the human NHE1, NHE5, NHE8 and NHE10 sequences as query sequences for each subgroup, respectively. The sampled sequences were aligned by using Clustal $W$ implemented in the Jalview suite.

l-tasser and pGenTHREADER were used for identifying the sequences of the proper crystallized template structures and for building a pairwise sequence structure alignment for the following 3D modeling step according to protocols described in Pierri et al. (2010). SwissPDBViewer was used for generating 3D models of NHE1 and NHE10. PyMOL was used for comparative analyses of the generated $3 \mathrm{D}$ models and the crystallized structure used as template for protein modeling according to protocols described in Pierri et al. (2010, 2016).

Autodock was used for docking cariporide in NHE1- and NHE10-binding regions according to protocols described in Pierri et al. (2010) and Todisco et al. (2016). The docking analyses were performed using a gridbox, whose center was in correspondence of the $\mathrm{Tl}^{+}$ion. The employed gridbox consists of $35 \times 35 \times 35$ gridpoints in the $x-y-z$ Cartesian space. The distance between each gridpoint of the gridbox was set to $0.281 \AA$. The parameter 'rmstol' was set to 1.5 ; the parameter 'ga_pop_size' was set to 50, the parameter 'ga_num_evals' was set to $2.5 \times 10^{5}$, the parameter 'ga_num_generations' was set to $2.7 \times 10^{4}$. The number of top individuals to survive to the next generation was set to 5 and a ranked cluster analysis of the 50 cariporide poses generated was performed.

\section{Sperm motility assessment by Computer-Assisted Sperm Analysis (CASA)}

The effect of cariporide on sperm motility was analyzed by the HTM-IVOS Computer-Assisted Sperm Analyzer (CASA), version 12.3 (Hamilton-Thorne Biosciences, MA, USA). Semen samples $(0.2 \mathrm{~mL} / \mathrm{straw})$ from a single ejaculate frozen at the concentration of $1 \times 10^{8}$ sperm cells $/ \mathrm{mL}$ were rapidly thawed in water bath at $38.5^{\circ} \mathrm{C}$ for $30 \mathrm{~s}$. Subsequently, cells underwent the swim-up procedure in $\mathrm{NaCl}$ medium. After in vitro exposure under inhibiting or control conditions, the supernatants $(0.6 \mathrm{~mL})$ were recovered and centrifuged at $300 \mathrm{~g}$ for $10 \mathrm{~min}$. The pellets were resuspended in $100 \mu \mathrm{L}$ $\mathrm{NaCl}$ medium. CASA analyses were conducted at $38.5^{\circ} \mathrm{C}$ by loading $4 \mu \mathrm{L}$ of sperm samples on specific slide chambers, $20 \mu$ in depth (Leja 4, Leja Products B.V., The Netherlands). For each sample, 3 independent cameras were used and a total of 24 random fields (8 fields/camera) were counted. The following parameters were measured: the percentage of motile spermatozoa (total motility, \%); the percentage of progressively motile spermatozoa (progressive motility, \%); the average path velocity (VAP, $\mu \mathrm{m} / \mathrm{s})$, calculated as the curvilinear trajectory of the sperm head; the straight-line rectilinear velocity $(\mathrm{VSL}, \mu \mathrm{m} / \mathrm{s})$, calculated as the velocity of the sperm head along the trajectory between the first and the last spotted position; the curvilinear velocity $(\mathrm{VCL}, \mu \mathrm{m} / \mathrm{s})$, calculated as the velocity of the sperm head along the total covered distance and the amplitude of the lateral head displacement (ALH, $\mu \mathrm{m})$. Furthermore, sperm velocity distribution was analyzed by identifying four sperm cell movement subcategories based on ram-specific VAP cutoff, as reported in the HTM-IVOS CASA system, version 12.3 software: percentage of rapid cells (fraction of cells moving with VAP $>75 \mu \mathrm{m} / \mathrm{s}$; rapid, \%); percentage of medium speed cells (fraction of cells moving with VAP values ranging from 21.9 to $75 \mu \mathrm{m} / \mathrm{s}$; medium, \%); percentage of slow cells (fraction of cells with VAP $<21.9-$ $75 \mu \mathrm{m} / \mathrm{s}$; slow, \%) and percentage of static cells (fraction of cells not moving at all; static, \%). Sperm motility parameters were defined as previously reported in the IVOS software manual, and in Mortimer and Maxwell (1999), Palacin et al. (2013), Najafi et al. (2017). Statistical comparisons were made by using the unpaired Student's $t$-test.

\section{IVF assay}

Ovaries from juvenile ( $<6$ months of age) sheep were recovered at local slaughterhouses in accordance with the Council Directive 89/556/ECC and subsequent modifications. Ovaries were processed by the slicing procedure and only cumulusoocyte complexes (COCs) with intact cumulus cell layers and a homogeneous cytoplasm were selected. In vitro maturation (IVM) was performed as previously reported (Martino et al. 2016). Medium TCM-199 with Earle's salts, buffered with $4.43 \mathrm{mM}$ 4-(2-hydroxyethyl)-1-piperazineethanesulfonic acid (HEPES), $33.9 \mathrm{mM}$ sodium bicarbonate and supplemented with $0.1 \mathrm{~g} / \mathrm{L}$ L-glutamine, $2 \mathrm{mM}$ sodium pyruvate, $2.92 \mathrm{mM}$ calciumL-lactate pentahydrate (Fluka 21175; Serva Feinbiochem), $50 \mu \mathrm{g} / \mathrm{mL}$ gentamicin, $10 \%(\mathrm{v} / \mathrm{v})$ fetal calf serum (FCS), $10 \mu \mathrm{g} /$ $\mathrm{mL}$ ovine follicle-stimulating hormone (FSH) and $20 \mu \mathrm{g} / \mathrm{mL}$ ovine luteinizing hormone (LH), $1 \mu \mathrm{g} / \mathrm{mL} 17$ beta estradiol was used. COCs were placed in $400 \mu \mathrm{L}$ of medium/well of a four-well dish (Nunc Intermed, Roskilde, Denmark) covered with pre-equilibrated lightweight paraffin oil and cultured for $24 \mathrm{~h}$ at $38.5^{\circ} \mathrm{C}$ under $5 \% \mathrm{CO}_{2}$ in air. After IVM culture, oocytes underwent partial cumulus cell removal by incubation in TCM 199 with $20 \%$ FCS and aspiration in and out of finely drawn glass pipettes.

Fresh sperm, collected as described earlier, or frozen semen samples $(0.2 \mathrm{~mL} / \mathrm{straw})$ from a single ejaculate at the concentration of $1 \times 10^{8}$ sperm cells $/ \mathrm{mL}$, underwent the swim-up procedure (Martino et al. 2016) in $\mathrm{NaCl}$ medium under inhibiting or control conditions. The final sperm concentration of $1 \times 10^{6}$ sperm cells $/ \mathrm{mL}$ was added to $400 \mu \mathrm{L}$ of IVF culture medium (HEPES-buffered Tyrode's-lactate pyruvate medium containing $10 \mu \mathrm{g} / \mathrm{mL}$ heparin) containing in vitro matured oocytes (see above). Spermatozoa and oocytes (5-20 oocytes per well) were kept together for $24 \mathrm{~h}$ at $38.5^{\circ} \mathrm{C}$ under $5 \% \mathrm{CO}_{2}$ in air. On the day after IVF, oocytes were assessed for signs of fertilization. To evaluate nuclear chromatin, oocytes underwent cumulus and corona cell removal and were fixed 
in $3.8 \%$ buffered formaldehyde solution, stained with $2.5 \mu \mathrm{g} /$ $\mathrm{mL}$ Hoechst 33258 (Sigma) in 3:1 (v/v) glycerol/PBS and mounted on microscope slides. Oocytes were observed under an epifluorescence microscope (Nikon Eclipse 600; 400× magnification) equipped with B-2 A (346 nm excitation/460 nm emission) filter. Normal fertilization was defined by the presence of two pronuclei (PN) and two polar bodies (PB). Oocytes found cleaved (two- to four-cell stage), showing two to four regular-shaped blastomeres with a normal nucleus within each blastomere, were also considered as normally fertilized. Presence of a swollen sperm head, a single PN with signs of the sperm cell in the cytoplasm, and abnormal cleavage (irregular shape blastomeres with irregular number of nuclei) were considered to represent retarded, arrested or abnormal fertilization and were grouped together as abnormal. Parthenogenetically activated oocytes showing one PN and one PB and oocytes showing the metaphase II with or without the intact sperm cell were classified as unfertilized. Nuclear chromatin status of other unfertilized oocytes was classified as follows in relation to the stage at which meiotic development was interrupted: germinal vesicle (GV), metaphase to telophase I (MI) and metaphase II (MII) with or without the chromatin of the first PB. Oocytes showing either multipolar meiotic spindle or irregular chromatin clumps or no chromatin were considered as abnormal. Oocytes with fragmented or shrunken cytoplasm were classified as degenerated. Oocyte fertilization rates were compared between treated and control groups by chi-square test with the Yates correction for continuity.

\section{Results}

\section{Functional characterization of NHE activity in ram spermatozoa}

Before proceeding with specific inhibition tests, the overall NHE activity in the sperm cell was analyzed, as literature data are lacking in this species. NHE activity was evaluated by $\mathrm{pH}_{\mathrm{i}}$ measurement carried out using the BCECF-AM fluorescent dye. The calibration curve of the fluorescence ratio as a function of $\mathrm{pH}_{\mathrm{i}}$ is shown as Fig. 1A. As can be observed, the curve is linear over a $\mathrm{pH}_{\mathrm{i}}$ range of 6.0-7.5, similarly to what was previously reported in other cell systems (Wang et al. 2003). The calibration curve was used in all subsequent experiments to convert fluorescence ratios $(500 / 450 \mathrm{~nm})$ into $\mathrm{pH}_{\mathrm{i}}$ values. Consistently with data reported in sperm cells of other mammalian species (Mannowetz et al. 2012), the resting $\mathrm{pH}_{\mathrm{i}}$ in fresh ram spermatozoa under noncapacitating conditions in a medium containing $\mathrm{NaCl}$ at physiological concentration $(150 \mathrm{mM})$ was $7.04 \pm 0.03$, as evaluated in 22 independent experiments. At this $\mathrm{pH}$ value, the $\mathrm{Na}^{+} / \mathrm{H}^{+}$exchanger is normally quiescent. As it rapidly becomes activated as soon as the acidity of the cytoplasm increases, we therefore characterized the protein activity, namely its ability to extrude $\mathrm{H}^{+}$ions, in non-capacitated sperm cells subjected to intracellular acidification by an ammonium chloride pulse (see 'Materials and methods' section). After $\mathrm{NH}_{4} \mathrm{Cl}$ acid
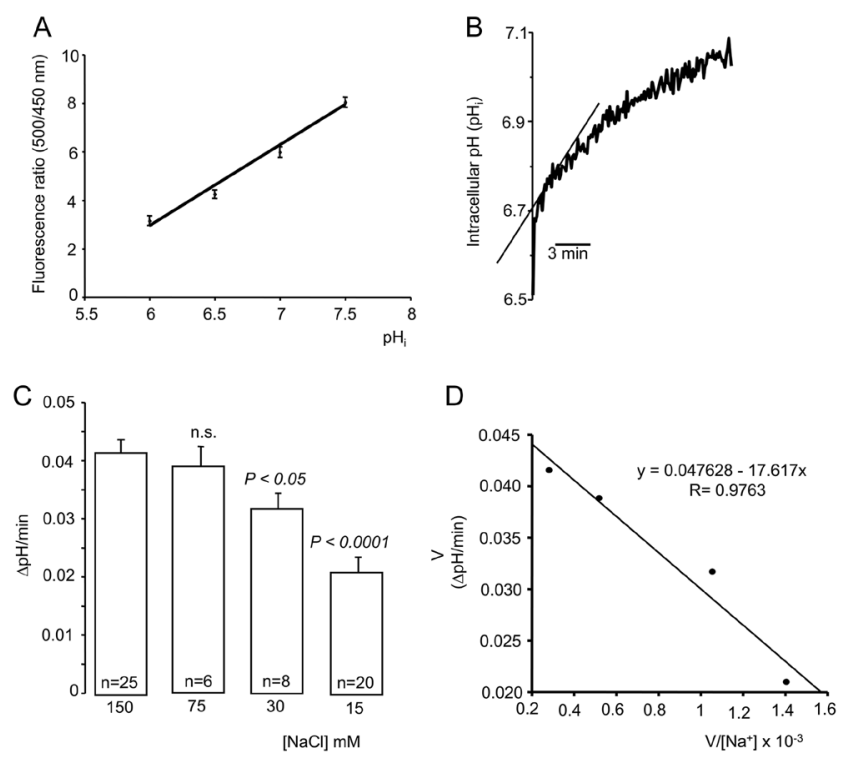

Figure 1 (A) Calibration curve of intracellular $\mathrm{pH}\left(\mathrm{pH}_{\mathrm{i}}\right)$. Ram spermatozoa were loaded with the fluorescence dye BCECF-AM, and the high- $\mathrm{K}^{+} /$nigericin technique was used to clamp $\mathrm{pH}_{\mathrm{i}}$ to extracellular $\mathrm{pH}\left(\mathrm{pH}_{\mathrm{e}}\right) \cdot \mathrm{pH}_{\mathrm{e}}$ was varied from 6.0 to 7.5. Data from 8 experiments performed on 3 rams were linearly fitted. (B, C and D) NHE activity in ram spermatozoa. Panel B presents a typical trace of $\mathrm{pH}_{\mathrm{i}}$ recovery when spermatozoa were resuspended in $\mathrm{Na}^{+}$medium $(150 \mathrm{mM})$ after an acid load. The effect of change in external $\mathrm{Na}^{+}$on pHi recovery is shown in panel C. A decrease of $\left[\mathrm{Na}^{+}\right]_{\mathrm{e}}$ from 150 to $15 \mathrm{mM}$ slowed down NHE1 rate. Panels B and C represent the results obtained from several experiments carried out on sperm from three different rams. A Woolf-Augustinsson-Hofstee plot of the same data is shown in panel D.

load $(40 \mathrm{mM}$, for $10 \mathrm{~min})$, internal $\mathrm{pH}$ was $6.72 \pm 0.008$ ( $n=108$ independent experiments). In all subsequent analysis, the $\mathrm{Na}^{+} / \mathrm{H}^{+}$exchange activity was therefore evaluated when reaching the above $\mathrm{pH}$ value. Recovery from acid load was observed when spermatozoa were suspended in the $150 \mathrm{mM} \mathrm{NaCl}$ medium (Fig. 1B), with a rate of $\mathrm{Na}^{+} / \mathrm{H}^{+}$exchange of $0.042 \Delta \mathrm{pH} / \mathrm{min}$. On the contrary, no recovery of $\mathrm{pH}_{\mathrm{i}}$ was observed when spermatozoa were suspended in a $\mathrm{Na}^{+}$-free medium, thus demonstrating that no proton extrusion pathway, with significant transport rate, exists in the absence of sodium (data not shown).

\section{NHE kinetic parameters in sperm cells}

In order to provide indirect evidence that NHE plays a role in intracellular $\mathrm{pH}$ regulation in the sperm cell, we performed the same experiments as described earlier in the presence of increasing extracellular $\mathrm{Na}^{+}$concentrations. In detail, the initial $\mathrm{pH}_{\mathrm{i}}$ recovery rate was measured in the presence of 15 ( $n=20$ independent experiments), 30 ( $n=8$ independent experiments), 75 ( $n=6$ independent experiments) and 150 ( $n=25$ independent experiments) $\mathrm{mM}$ extracellular sodium (Fig. 1C). Significant decreases of NHE activity were observed at the lower extracellular 
$\mathrm{Na}^{+}$concentrations (15 and $30 \mathrm{mM}$ ) compared to the physiological concentration. Analysis of the same data by the Woolf-Augustinsson-Hofstee equation showed an apparent $K_{\mathrm{m}}$ value for external $\mathrm{Na}^{+}$of $17.61 \mathrm{mM}$ in the sperm cell (Fig. 1D).

\section{Protein expression and localization in ram spermatozoa}

As we have decided to conduct the study of the functional mechanism of NHE1 on the ovine sperm model for its reproductive physiology features closer to those of human sperm compared with laboratory animals, it was necessary to preliminarily analyze NHE1 expression on ovine sperm. In order to increase the specificity of the analysis, and due to the lack of NHE1 antibodies specifically raised against cell antigens of the ovine species, the study was conducted in a double confirmation mode, as two anti-NHE1 antibodies, for two different regions of the same protein, were used, namely the polyclonal anti-NHE1 against the intracellular C-terminus adopted in the previous study by Woo et al. (2002), and a monoclonal antibody raised against the extracellular $\mathrm{N}$-terminus (Yang et al. 2013). Furthermore, in silico analysis of NHE1, NHE5, NHE8 and NHE10 protein sequences highlighted remarkable variability in length and amino acid composition at both the $\mathrm{N}$-terminus and at the C-terminus (Supplementary Figs 1 and 2, respectively, see section on supplementary data given at the end of this article) among the four isoforms, that is consistent with the proposed high selectivity of the two antibodies adopted in this study vs NHE1. Indeed, both antibodies detected a single band with an apparent molecular mass of $85 \mathrm{kDa}$ (Fig. 2A). A band of similar size, but weaker intensity, was detected in ram ghosts (red blood cells membranes), which were used as positive controls, due to the previously reported notion that they express NHE1 as a major sodium-proton exchanger isoform in several mammalian and not mammalian species (Pedersen \& Cala 2004).

The immunofluorescence analysis revealed, consistently for both antibodies, the presence of positive signals at the equatorial region of the sperm head, in the mid-piece and the proximal segment of the flagellum (Fig. 2B). The lack of immunoreactivity in sperm cells, where the primary antibody was omitted, confirmed the labeling specificity (Fig. 2C).

\section{Effects of $\mathrm{Na}^{+} / \mathrm{H}^{+}$exchanger inhibitors on sperm intracellular $\mathrm{pH}$ regulation}

To add evidence for the possible involvement of the NHE isoform 1 in sperm $\mathrm{pH}_{\mathrm{i}}$ regulation, we adopted two selective NHE1 inhibitors, DMA and cariporide. Data were obtained in sperm cells exposed to acid load, and then incubated for $30 \mathrm{~min}$ in $\mathrm{Na}^{+}$-free medium in
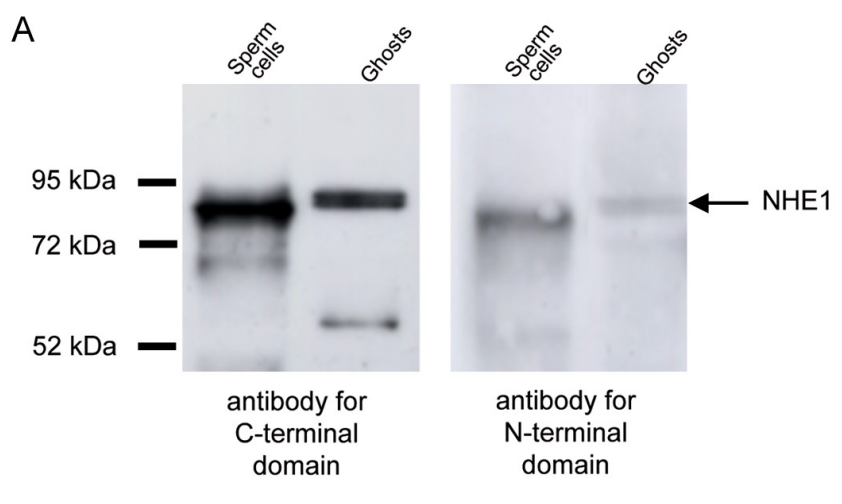

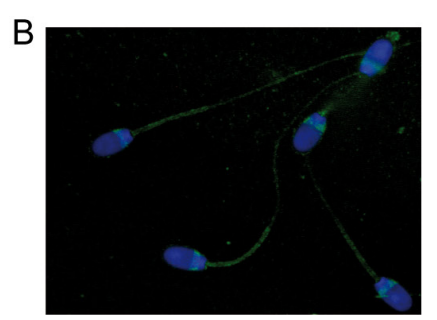

Anti-NHE1

C-terminal domain

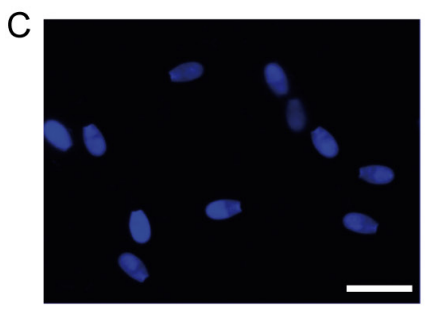

Negative Control

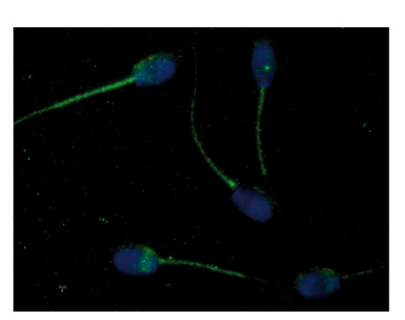

Anti-NHE1 $\mathrm{N}$-terminal domain

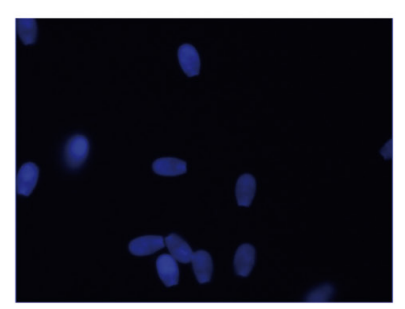

Negative Control
Figure 2 NHE1 expression and localization on ram sperm cells. (A) Representative Western blot of ram whole sperms and red blood lysates (ghosts) using a monoclonal anti-NHE1 antibody (1:400 dilution), which specifically binds the amino-terminal domain and a polyclonal anti-NHE1 antibody (1:400 dilution) against the C-terminus epitope. The two antibodies detected an apparent band of approximately $85 \mathrm{kDa}$ in both cell types. (B) Representative photomicrographs of NHE1 localization in ram sperm cells investigated through immunofluorescence by using the same anti-NHE1 polyclonal antibody (1:200 dilution) against the C-terminus domain (left panel) and the monoclonal antibody anti-NHE1 (1:200 dilution) against the N-terminus domain (right panel) as used in the Western blot analysis. Intense staining was observed on the mid-piece surface of the sperm flagellum, together with a weaker signal at the equatorial region of the sperm head. Nuclei are counterstained with DAPI (blue). (C) As negative control, spermatozoa were incubated only with FITC-conjugated secondary antibodies. Only DAPI-stained nuclei were detectable. Scale bar: $10 \mu \mathrm{m}$.

the presence of each inhibitor, followed by incubation under physiological $\mathrm{Na}^{+}$concentrations. As shown in Fig. 3, both inhibitors significantly reduced $\mathrm{pH}_{\mathrm{i}}$ recovery, with cariporide displaying a stronger effect (85\% inhibition with $P<0.001$ vs $50 \%$ inhibition with $P<0.01$, respectively). 


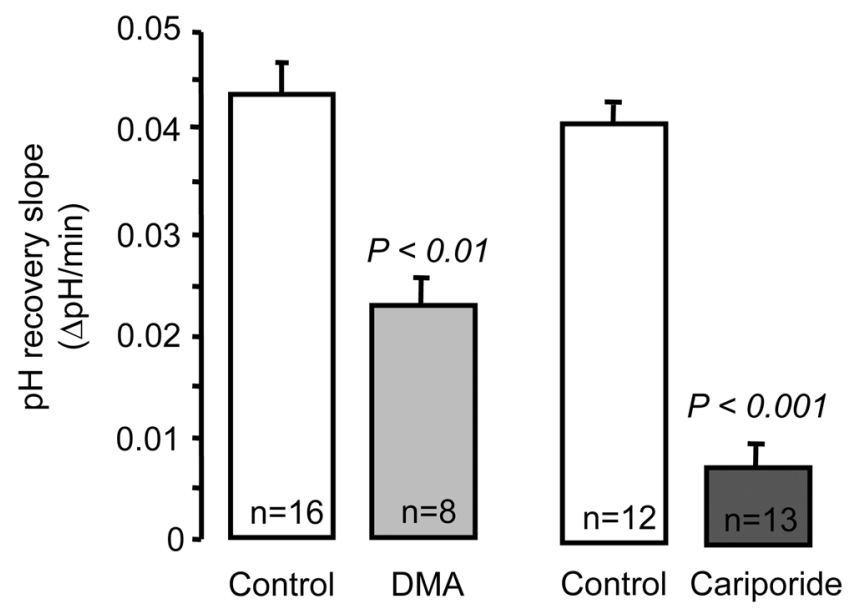

Figure 3 Effect of DMA and cariporide treatments on cytoplasmic $\mathrm{pH}$ recovery. The effect of DMA $(10 \mu \mathrm{M})$ and cariporide $(10 \mu \mathrm{M})$ on the rate of $\mathrm{pH}_{\mathrm{i}}$ recovery after acidification of non-capacitated spermatozoa was evaluated by the ammonium pulse technique. Sperm cells were incubated with DMA or cariporide for $30 \mathrm{~min}$ in the $\mathrm{Na}^{+}$-free medium and then added in $\mathrm{NaCl}$ medium $(150 \mathrm{mM})$. Results are means \pm S.E. from several experiments carried out on sperm from three different rams.

\section{Protein sequence alignment, 3D modeling and docking results}

From multiple sequence alignment of sodium-proton exchanger plasma membrane isoforms known to be expressed in sperm cells, NHE1 and NHE5 orthologs appear to share $85-90 \%$ of identical residues, whereas a greater variability is observed among NHE10 orthologs, sharing the $66-70 \%$ of identical residues. NHE1 and
NHE5 paralogs share the $40-50 \%$ of identical residues, whereas NHE1/5 shares only the $20-25 \%$ of identical residues with NHE10. Notably, NHE10 sequences have a C-terminus longer than the C-terminus observed in NHE1 and NHE5 paralogs (Supplementary Fig. 2). In general, NHE1, NHE5 and NHE10 share a common overall structure allowing them to work as $\mathrm{Na}^{+} / \mathrm{H}^{+}$ antiporters. In particular, NHE1/5/10 shows a wellconserved substrate ion-binding site and polar channel with the Pyrococcus abyssi $\mathrm{Na}^{+} / \mathrm{H}^{+}$antiporter (PaNhaP), whose full-length sequence shows the $23-27 \%$ of identical residues with NHE1, NHE5 and NHE10. From the PaNhaP crystal structure, it was observed that residues coordinating directly the ion substrate were E73 (helix 3) and D159 (helix 6), whereas D130 (helix 5) appeared to interact with the ion substrate via a water molecule. T129 (helix 5) and S155 (helix 6) also were proposed to participate in ion substrate coordination. A second channel crucial for $\mathrm{Na}^{+} / \mathrm{H}^{+}$antiport function was highlighted and consisted of residues D93, N158 and the ion pair E154/R337 that together with T129 separates the cavity hosting the ion substrate-binding site from the polar channel (Goswami et al. 2011, Wohlert et al. 2014).

From multiple sequence alignment, it is observed that E73 from PhNhaP has an acidic counterpart in NHE1 (HsaNHE1, D172; OarNHE1, D172) and NHE5 (HsaNHE5, D118; OarNHE1, D120) paralogs, whereas in NHE10 that acidic residue is replaced by a hydrophilic residue (HsaNHE10, T90; OarNHE10, T109). It is also observed that D159 is conserved in NHE1 (HsaNHE1, D267; OarNHE1, D267) and NHE5 (HsaNHE5, D214; OarNHE5, D216), whereas in NHE10, it is replaced with

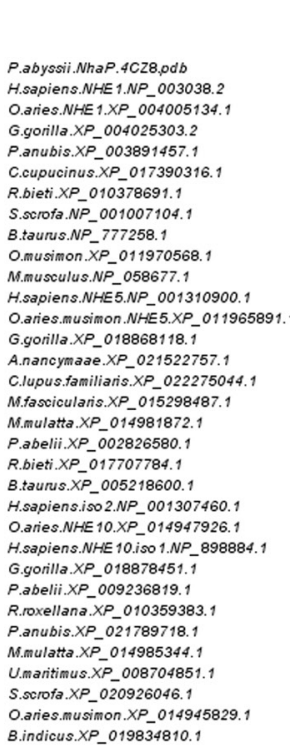
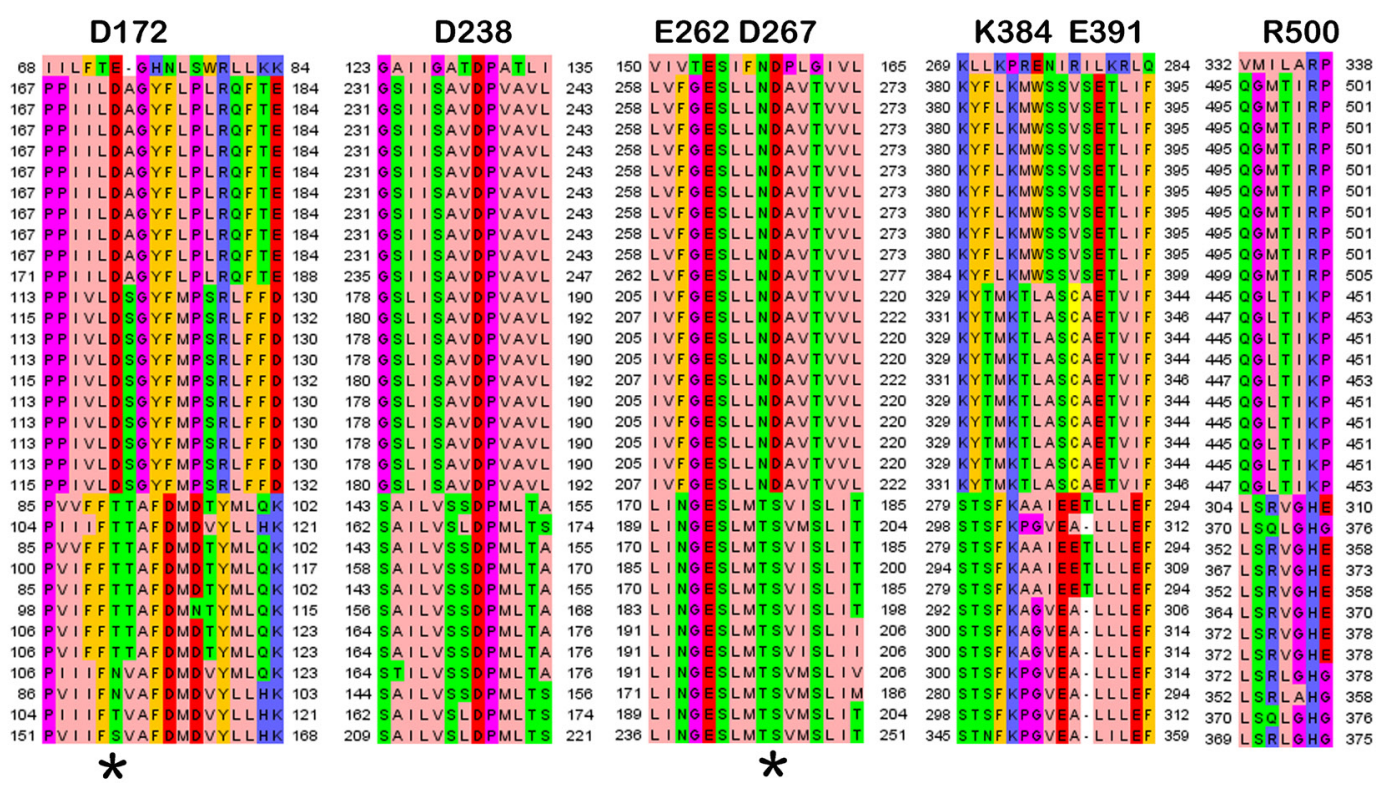

Figure 4 An extract of the multiple sequence alignment is reported by using the Jalview Zappo color style. Labels of residues involved in the ion substrate binding site and in the polar channel are reported upon the alignment. ${ }^{* \prime}{ }^{\prime}$ indicates the two residues playing a crucial role in the affinity for cariporide. 
a hydrophilic residue (HsaNHE10, S179; OarNHE10, S198) (Fig. 4).

The resulting $3 \mathrm{D}$ models generated by using SwissPDBViewer include the NHE1, NHE5 and NHE10 portions involved in the antiport mechanism and consisted of 13 helices. In each of the 3 antiporters, helices $\mathrm{H} 1-\mathrm{H} 3, \mathrm{H} 7-\mathrm{H} 10$ form the dimer interface, whereas helices $\mathrm{H} 4-\mathrm{H} 6, \mathrm{H} 11-\mathrm{H} 13$ form a polar channel according to Goswami et al. (2011) and Wohlert et al. (2014). For a representation of the dimers, refer to Supplementary Fig. 3.

PyMOL was used for superimposing the generated 3D models with the crystallized $\mathrm{Na}^{+} / \mathrm{H}^{+}$antiporter from $P$. abyssi (PhNhaP). Thus, it was possible to obtain $\mathrm{Tl}^{+}$ion and water molecules crucial for protein function in the proper binding site of the human paralogs through the superimposition with the PhNhaP. Thanks to structure superimposition it was observed that residues within $4 \AA$ from $\mathrm{Tl}^{+}$ion and cariporide (aligned with those proposed as crucial for PaNhaP) in the human NHE1 are D172, V237, D238, V240, E262, S263, N266, D267 (see the corresponding conserved NHE5 residues from the alignment of Fig. 4), whereas in the human NHE10 the corresponding residues are T90, S149, D150, M152, E174, S175, T178, S179 (Fig. 5). Notably, other residues important for cariporide recognition (from docking analyses) in NHE1 are K384 and E391, whereas in NHE10, the corresponding residues are K283 and E288 (Fig. 5).
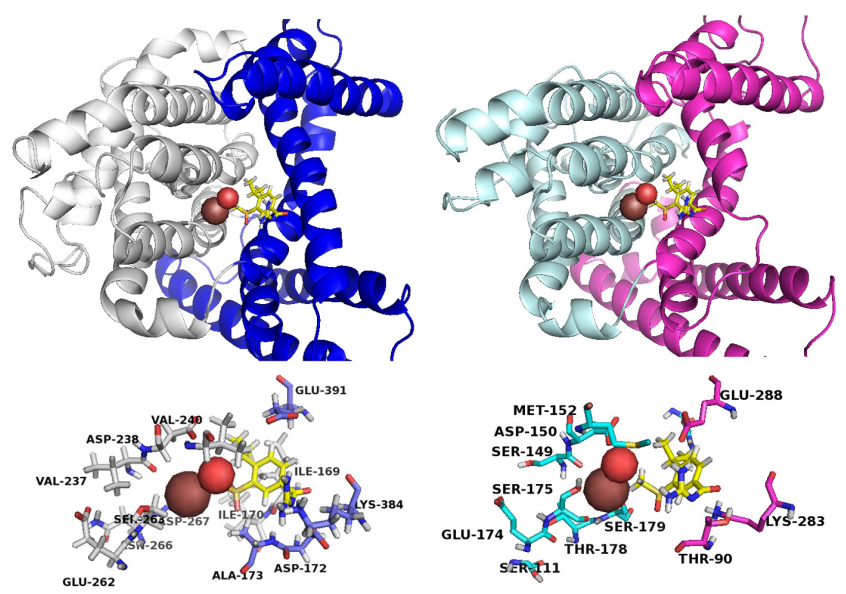

Figure 5 3D comparative models of the human NHE1 and NHE10. The top view of a single monomer of NHE1 (left panels) and NHE10 (right panels) are reported in cartoon representation. Polar channels formed by helices $\mathrm{H} 1-\mathrm{H} 3$ and $\mathrm{H} 7-\mathrm{H} 10$ are reported in gray (NHE1) and cyan (NHE10), whereas helices $\mathrm{H} 4-\mathrm{H} 6$ and $\mathrm{H} 11-\mathrm{H} 13$ at the dimer interface are reported in blue (NHE1) and magenta (NHE10) (Supplementary Fig. 3). Residues within $4 \AA$ from cariporide (yellow sticks) and $\mathrm{Tl}^{+}$ion (brown sphere) are reported in sticks (white and blue for NHE1; cyan and magenta for NHE10).

\section{Effect of cariporide on sperm motility}

As cariporide displayed a stronger inhibiting effect compared with DMA, and considering that the aforementioned protein alignment data supported the knowledge of its selectivity toward NHE1, this inhibitor was selected for being used in subsequent motility and fertility experiments.

The effect of cariporide on sperm cell motility parameters was assessed by CASA analysis at the concentration of $20 \mu \mathrm{M}$ and at different exposure times (60, 120 and $180 \mathrm{~min}$ ). Exposure to cariporide induced a statistically significant reduction of total motility at 120 and $180 \mathrm{~min}(P<0.05$; Fig. 6A), whereas progressive motility was not affected at any examined time (Fig. 6B). However, by examining sperm samples into four subcategories of progressive sperm movement (rapid, medium, slow and static), it was possible to observe that the cariporide treatment significantly reduced the percentage of rapid cells $(P<0.05$; Fig. 6C) and increased the percentage of medium $(P<0.01)$, slow (from $P<0.05)$ and static cells $(P<0.05$; Fig. 6D, E and F). Similarly, sperm velocity sub-parameters (VAP, VSL, VCL) were significantly reduced after $60 \mathrm{~min}(P<0.0001$; Fig. 7A, B and C). At 180 min exposure, only VCL was reduced $(P<0.01$; Fig. $7 \mathrm{C})$. Furthermore, cariporide induced a reduction of ALH after $120-(P<0.05)$ and $180(P<0.01)$-min exposure (Fig. 7D). Notably, VSL, VCL and ALH are also considered as capacitationrelated sperm parameters.

\section{Effects of cariporide on sperm fertilizing ability}

Assessing the effects of cariporide on IVF rate, under the same conditions adopted for the characterization of the exchanger activity and sperm motility testing, was a hard technical issue as the fertilization protocol requires specific media containing bicarbonate. Fertilization experiments were initially carried out using fresh semen. Poor fertilization rates with no significant differences between cariporide-exposed and control samples were observed (Table 1, left column). This result was thought to be related to poor capacitation rate occurring during sperm swim-up in $\mathrm{NaCl}$ medium. Therefore, experiments were repeated using frozen/thawed sperm, which is known to 'per se' display a fraction of capacitated cells (Perez et al. 1996). As expected, the fertilization rates with frozen/thawed sperm were significantly increased $(P<0.05)$ compared with fresh sperm. However, even in this case, no significant differences were found between cariporide-exposed and control samples (Table 1, right column).

\section{Discussion}

All our experiments were performed in the absence of bicarbonate, which allowed us to exclude the 

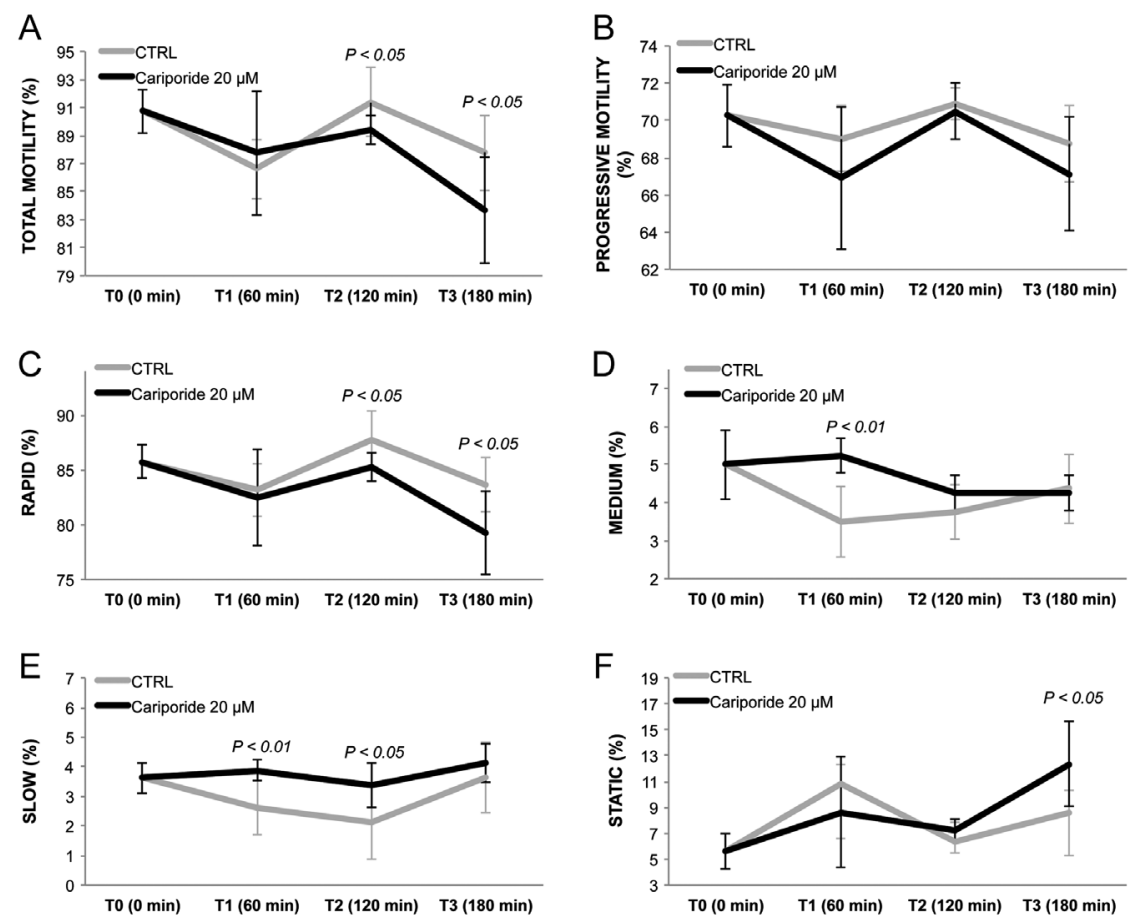

Figure 6 Time-dependent effect of cariporide on total and progressive motility of ram sperm cell analyzed at three different exposure times $(60,120$ and $180 \mathrm{~min})$ by Computer-Assisted Sperm Analysis (CASA). The reduction of the sperm motility was assessed by analyzing total motility (A), progressive motility (B) and four subcategories of progressive movement: rapid, medium, slow and static (C, D, E and F). involvement of bicarbonate-dependent alkalizing mechanisms known from the literature to be involved in cell pH regulation (Martins et al. 2014). As such, we were able to evaluate, for the first time in sperm cells, the kinetic parameters of $\mathrm{NHE}$, and to highlight the importance of the sodium gradient on the export of $\mathrm{H}^{+}$. Moreover, the observed sodium affinity for the NHEbinding site was consistent with previous evidences of $\mathrm{NHE}$ exhibiting $K_{\mathrm{m}}$ values ranging $5-50 \mathrm{mM}$ in other cell types and other species (Masereel et al. 2003, Goswami et al. 2011, Wohlert et al. 2014).

Most of the literature on NHE1 expression in different cell systems from various mammalian species describes a band of approximately 95-110 kDa (Leung et al. 2001, Slepkov et al. 2005, Cuello et al. 2007), the different molecular weights likely reflecting distinct glycosylation levels. However, consistent with our results, a $\sim 85 \mathrm{kDa}$
NHE1 protein was observed in rat in palmar skin and renal inner medulla (Nejsum et al. 2005) and in immortalized proximal tubule cells (Carraro-Lacroix et al. 2006). Similarly, a NHE1 band of $\sim 80 \mathrm{kDa}$ was described in rat efferent ductal and cauda epididymal epithelial cells (Leung et al. 2001), rat pancreas (Roussa et al. 2001) and adult rat ventricular myocytes (Cuello et al. 2007). A lighter NHE1 band (70 kDa) was also observed in bovine, basolateral membrane of fresh corneal endothelial cells (Rimmer 1999). Notably, Woo et al. (2002) firstly reported the expression of NHE1 in rat sperm cells through Western blot analysis, highlighting the detection of a single $95 \mathrm{kDa}$ band. On the other hand, Wang et al. (2003) reported, in mouse sperm cells, a single band of about $130 \mathrm{kDa}$ for the NHE10 isoform. Based on the above-mentioned results, the protein observed in the present study may reflect low glycosylation levels
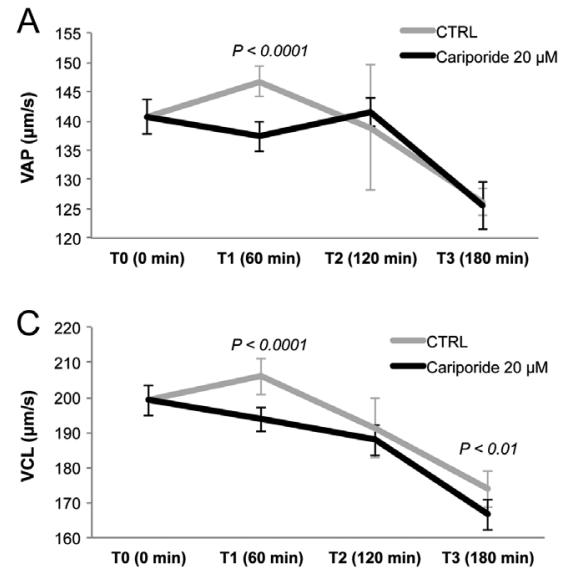

www.reproduction-online.org
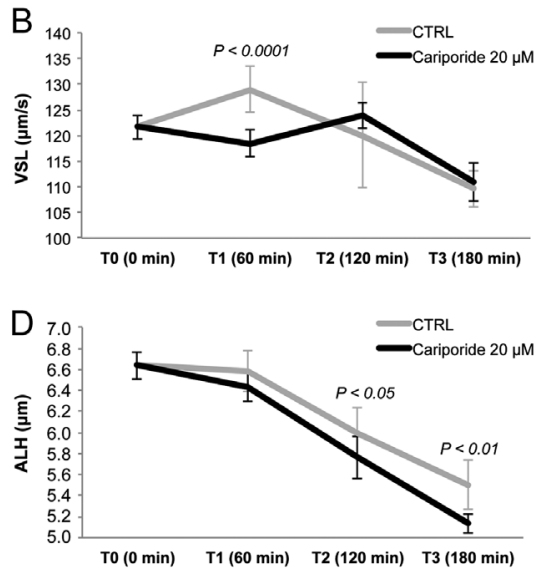

Figure 7 Effects of cariporide on CASA velocity sub-parameters (VAP, VCL, VSL) (panels A, B and $\mathrm{C}$ ), and $\mathrm{ALH}$, a capacitation-related parameter (D). The analysis was conducted at $38.5^{\circ} \mathrm{C}$. For each sample, three independent cameras were used and a total of 24 random fields ( 8 fields/camera) were counted. Statistical comparisons were made using the unpaired Student's $t$-test, adopting a significance threshold of $P<0.05$. 
Table 1 Effects of cariporide on the fertilizing ability of ram sperm cells.

\begin{tabular}{|c|c|c|c|c|}
\hline Cultured oocytes, $n$ & 23 & 24 & 50 & 70 \\
\hline Swim-up & CTRL & Cariporide & CTRL & Cariporide \\
\hline Sperm type & Fresh & Fresh & Frozen & Frozen \\
\hline Swim-up medium & $\mathrm{NaCl}$ & $\mathrm{NaCl}$ & $\mathrm{NaCl}$ & $\mathrm{NaCl}$ \\
\hline IVF medium & TALP - FERT & TALP - FERT & TALP - FERT & TALP - FERT \\
\hline Sperm $(/ \mathrm{mL})$ & $1 \times 10^{6}$ & $1 \times 10^{6}$ & $1 \times 10^{6}$ & $1 \times 10^{6}$ \\
\hline Oocytes evaluated after IVM, $n$ & 23 & 24 & 45 & 70 \\
\hline Germinal vesicle & 7 & 2 & 9 & 19 \\
\hline Metaphase I to Telophase I & 5 & 7 & 2 & 6 \\
\hline Metaphase II & 7 & 8 & 18 & 18 \\
\hline Abnormal & 0 & 1 & 1 & 4 \\
\hline Activated (/eval post IVM: \%) & 2 & 1 & 1 & 4 \\
\hline Maturation rate $(\%)$ & $11(47.8)$ & $14(58.3)$ & $32(71.1)$ & $37(52.9)$ \\
\hline 2PN2PB (/matured: \%) & $1(9.1)$ & $3(21.4)$ & $8(25)$ & $12(32.7)$ \\
\hline 2PN2PB (/eval post IVM: \%) & $1(4.3)$ & $3(12.5)$ & $8(17.8)$ & $12(17.1)$ \\
\hline $1 \mathrm{PN}+\operatorname{spz} \operatorname{dec}(/ /$ fert: \%) & 0 & 1 & 0 & 0 \\
\hline$>2 \mathrm{PN}$ (/fert: \%) & 1 & 1 & 6 & 7 \\
\hline Fertilization rate (/matured: \%) & $2(18.2)$ & $5(35.7)$ & $14(43.7)$ & $19(51.3)$ \\
\hline Fertilization rate (/eval post IVM: \%) & $2(8.7)^{\mathrm{a}}$ & $5(20.8)$ & $14(31.1)^{b}$ & $19(27.1)$ \\
\hline
\end{tabular}

Chi-square test: ${ }^{\mathrm{a}, \mathrm{b}} \mathrm{P}<0.05$.

IVF, in vitro fertilization; IVM, in vitro maturation; PB, polar body; PN, pronucleus; spz, spermatozoa; TALP, Tyrode's-lactate pyruvate medium.

and/or other post-transcriptional modifications in ram sperm cells NHE1, likely a species-specific feature, as no difference was observed between sperm and red blood cells in sheep.

Concerning the localization at the flagellum level, the pattern observed in this study was clearly different from that reported in mouse sperm for the two described sperm-specific (sNHE) and testis-specific (mtsNHE) isoforms, both observed only in the main piece (Wang et al. 2003, Liu et al. 2010) thus adding evidence to the notion of specificity of the antibodies adopted here. Similar to what was observed by Woo et al. (2002) in rat sperm cells, we observed the expression of NHE1 at the mid-piece and in the proximal segment of the flagellum, while the presence of NHE1 on the sperm head is described here for the first time. Further, the use of specific NHE1 inhibitors, DMA and cariporide, allowed us to evidence, for the first time, the functional expression of this NHE isoform in sperm cells through evaluation of its involvement in intracellular $\mathrm{pH}$ regulation. Moreover, the in silico evidence that the human NHE1 protein has a remarkably different protein sequence and organization compared to $\mathrm{s} N \mathrm{HE}$ suggested that both cariporide and DMA may be inactive on that isoform, for which published inhibition studies are still missing. The observed difference in the NHE1 inhibition of intracellular $\mathrm{pH}$ regulation between the two drugs adopted in the present study likely reflects their chemical nature (Mihaila 2015). Indeed, cariporide has been previously demonstrated to be a more potent, specific and selective inhibitor of NHE1 than other NHE inhibitors of the amiloride class (Siyanov \& Baltz 2013).

It is known from the literature that $\mathrm{Na}^{+} / \mathrm{H}^{+}$antiporter proteins have in common a substrate ion-binding site (for sodium) and a polar channel deeply involved in the binding and $\mathrm{Na}^{+} / \mathrm{H}^{+}$antiport (Wohlert et al. 2014).
Wohlert and coworkers crystallized the sodium-proton antiporter from $\mathrm{PaNhaP}$ as dimer and each monomer was complexed with a thallium $\left(\mathrm{Tl}^{+}\right)$ion, another substrate of PaNhaP, for gaining new insights about $\mathrm{Na}^{+}$binding. The ion-binding site results are accessible from the cytoplasm but not from the extracellular side, which shows the inward-open conformation of PaNhaP (Wohlert et al. 2014).

For investigating the affinity of cariporide to NHE paralogs, we built multiple sequence alignments and 3D comparative models of human and ovine NHE1, NHE5 and sNHE (NHE10), the only NHE isoforms identified so far on the sperm plasma membrane (Martins et al. 2014). From multiple sequence alignments and comparative models, it was possible to observe that acidic residues (D172 and D267, human NHE1 numbering) conserved in PaNhaP, NHE1 and NHE5, involved in the binding of $\mathrm{Tl}^{+}$ and cariporide, are replaced with hydrophilic residues in NHE10 (T90 and S179). From docking analyses, it is possible to see that above all the replacement of D172 and D267 with T90 and S179, respectively, could be responsible for lowering the affinity of NHE10 for cariporide. In general, we can speculate that the arrangement of residues D172, D267, E391 and K384 in NHE1 (and NHE5) appears to establish stronger interactions with cariporide than those observable with T90, S179, E288 and K283 in NHE10. It is possible to observe several hydrophobic residues around D172, D267 and D238 in human NHE1 and their counterpart in human NHE5, namely D185, D214, but not D118 (Fig. 4). Most likely, the presence of residues 1170 and A173 close to D172 (human NHE1, Figs 4 and 5) at variance with the shorter V116 and the hydrophilic S119 (Fig. 4) may contribute to form in NHE1 a hydrophobicbinding pocket more stable than the one observed in NHE5. Thus, we can speculate that the hydrophobic 
character of NHE1-binding pocket, stronger than its counterpart in NHE5, may be responsible of more stable binding interactions with the hydrophobic moiety (the isopropyl - aromatic portion) of cariporide. This hypothesis is consistent with evidence from the work by Jinadasa et al. (2014) that, in AP-1 (NHE-deficient) cells, stably transfected with NHE1, after acid load with $\mathrm{NH}_{4} \mathrm{Cl}$, the intracellular $\mathrm{pH}$ recover was completely blocked at $1-10 \mu \mathrm{M}$ concentration of cariporide while substantially higher concentrations of cariporide (500$1000 \mu \mathrm{M}$ ) were required to block $\mathrm{pH}_{\mathrm{i}}$ recovery in AP-1 NHE5-expressing cells. Taken together, all the above considerations suggest that, in our study, the component of $\mathrm{Na}^{+}$-dependent $\mathrm{H}^{+}$efflux was more likely due to NHE1 activity rather than activity from other isoforms.

It has been long accepted that $\mathrm{pH}_{\mathrm{i}}$ is a vital regulator of spermatozoa motility (Darszon et al. 2007, Lishko \& Kirichok 2010, Fuster \& Alexander 2014). Because $\mathrm{NHE}$ is directly responsible for transporting $\mathrm{H}^{+}$outside the cell in exchange for extracellular $\mathrm{Na}^{+}$, its inhibition is supposed to induce proton accumulation inside the cell, thus potentially leading to the inhibition of sperm motility; we therefore tested the role of NHE on the motility of sperm cells via cariporide-dependent NHE1 inhibition. Obtained data acts as an evidence, for the first time, that the NHE1 isoform may play a role in the regulation of sperm motility in a large mammalian animal model. Indeed, Woo et al. (2002), by using ouabain, the inhibitor of $\mathrm{Na}^{+} / \mathrm{K}^{+}$-ATPase, questionably claimed the specific involvement of NHE1 in rat sperm motility. To our knowledge, no studies have been reported to date of a direct involvement of NHE1 in sperm motility by using its specific inhibitors. The present work represents a step forward in understanding the involvement of NHE in sperm motility, as by using a selective inhibitor, we suggest for the first time that the isoenzyme 1 of the $\mathrm{Na}^{+}$/ $\mathrm{H}^{+}$exchanger may affect a major motility parameter, such as total motility, and secondary kinetics parameters, such as VAP, VCL, VSL and ALH, some of them (VCL, VSL and ALH) being considered as indicators of sperm hyperactivated motility and capacitation.

The addition of cariporide had no effect on oocyte fertilization. This result could be explained considering that, despite the significant inhibitory effect on total motility and velocity parameters, a certain percentage of sperm cells may have retained normal motility, thus ensuring normal fertilization in vitro. Possible additional explanations may derive from the adopted swim-up and IVF procedures. In fact, during IVF, cumulus-oocyte complexes and sperm cells are co-cultured in vitro. Hence, we did not add cariporide in IVF medium, limiting inhibitor sperm exposure to the swim-up step, as it might have also altered $\mathrm{pH}$ regulation of the cumulus-oocyte complex. This would not have allowed to discriminate whether it exerted its inhibitory action on sperm or on the oocyte or both cell types. Moreover, during IVF, bicarbonate may have activated compensatory mechanisms of $\mathrm{pH}$ regulation in sperm, mediated by other membrane transporters (Freitas et al. 2017, Pereira et al. 2017). Another possible explanation could be the prolonged exposure time during IVF culture, in which cariporide may have progressively lost its inhibitory effect.

An in vivo study (Bell et al. 1999) described NHE1 knockout mice as fertile, although they were reported to be extremely fragile, with most of them dying before reaching adulthood. Though comparison between in vitro and in vivo studies is not straightforward, the results of our in vitro assays are in agreement with those of Bell et al. (1999), as we did not find correlation between the NHE1-dependent motility drop and fertilization rate. Moreover, it must be pointed out that upregulation of other proteins likely involved in the same biological pathway, e.g., NHE5 (Woo et al. 2002), sNHE, namely NHE10 (Wang et al. 2003), and mtsNHE (Liu et al. 2010), that can compensate for the loss of NHE1 activity in NHE1-null spermatozoa to maintain sperm motility and male fertility, may have played a role in explaining the sperm fertilizing ability, as reported by Bell et al. (1999) and in our IVF experiments.

In conclusion, this is the first study suggesting a possible functional involvement of NHE1 in sperm intracellular $\mathrm{pH}$ and motility regulation using NHE1 selective inhibition. Future production of recombinant cell lines, each expressing only single NHE isoforms, is therefore envisageable as they may represent a suitable model to screen for novel isoform-specific NHE inhibitors/activators enabling dissection of the relative contribution by different NHE isoforms in sperm cell function.

\section{Supplementary data}

This is linked to the online version of the paper at https://doi.org/10.1530/REP-17-0456.

\section{Declaration of interest}

The authors declare that there is no conflict of interest that could be perceived as prejudicing the impartiality of the research reported.

\section{Funding}

This work was supported by Fondazione Cassa di Risparmio di Puglia (http://www.fondazionecrpuglia.it/). N A M was granted by the project ONEV MIUR PONa3 00134-n.254/R\&C 18/05/2011 and the project GR-2011-02351396 (Ministry of Health, Young Researchers Grant 2011/2012). 


\section{Acknowledgements}

The authors dedicate this work to the memory of Prof. Dario Cianci, eminent researcher in the field of livestock science, for its long-standing role in promoting interdisciplinary interactions and for having inspired a generation of scientists through his personality. Authors would like to acknowledge Dr Maria Teresa Ferrara for contributing in data collection.

\section{References}

Baldi E, Luconi M, Bonaccorsi L \& Forti G 2002 Signal transduction pathways in human spermatozoa. Journal of Reproductive Immunology 53 121-131. (https://doi.org/10.1016/S0165-0378(01)00089-4)

Bell SM, Schreiner CM, Schultheis PJ, Miller ML, Evans RL, Vorhees CV, Shull GE \& Scott WJ 1999 Targeted disruption of the murine Nhe1 locus induces ataxia, growth retardation, and seizures. American Journal of Physiology 276 C788-C795. (https://doi.org/10.1152/ ajpcell.1999.276.4.C788)

Bradford MM 1976 A rapid and sensitive method for the quantitation of microgram quantities of protein utilizing the principle of proteindye binding. Analytical Biochemistry 72 248-254. (https://doi. org/10.1016/0003-2697(76)90527-3)

Carraro-Lacroix LR, Ramirez MA, Zorn TM, Reboucas NA \& Malnic G 2006 Increased NHE1 expression is associated with serum deprivationinduced differentiation in immortalized rat proximal tubule cells. American Journal of Physiology: Renal Physiology 291 F129-F139. (https://doi.org/10.1152/ajprenal.00290.2005)

Cox JF, Alfaro V, Montenegro V \& Rodriguez-Martinez H 2006 Computerassisted analysis of sperm motion in goats and its relationship with sperm migration in cervical mucus. Theriogenology 66 860-867. (https://doi. org/10.1016/j.theriogenology.2006.01.062)

Cuello F, Snabaitis AK, Cohen MS, Taunton J \& Avkiran M 2007 Evidence for direct regulation of myocardial $\mathrm{Na}+/ \mathrm{H}+$ exchanger isoform 1 phosphorylation and activity by $90-\mathrm{kDa}$ ribosomal S6 kinase (RSK): effects of the novel and specific RSK inhibitor fmk on responses to alpha1-adrenergic stimulation. Molecular Pharmacology 71 799-806. (https://doi.org/10.1124/mol.106.029900)

Darszon A, Trevino CL, Wood C, Galindo B, Rodriguez-Miranda E, Acevedo JJ, Hernandez-Gonzalez EO, Beltran C, Martinez-Lopez P \& Nishigaki T 2007 lon channels in sperm motility and capacitation. Society of Reproduction and Fertility Supplement 65 229-244.

Donowitz M, Ming Tse C \& Fuster D 2013 SLC9/NHE gene family, a plasma membrane and organellar family of $\mathrm{Na}(+) / \mathrm{H}(+)$ exchangers. Molecular Aspects of Medicine 34 236-251. (https://doi.org/10.1016/j. mam.2012.05.001)

Favia M, Mancini MT, Bezzerri V, Guerra L, Laselva O, Abbattiscianni AC, Debellis L, Reshkin SJ, Gambari R, Cabrini G et al. 2014 Trimethylangelicin promotes the functional rescue of mutant F508del CFTR protein in cystic fibrosis airway cells. American Journal of Physiology: Lung Cellular and Molecular Physiology 307 L48-L61. (https://doi.org/10.1152/ajplung.00305.2013)

Freitas MJ, Vijayaraghavan S \& Fardilha M 2017 Signaling mechanisms in mammalian sperm motility. Biology of Reproduction 96 2-12.

Fuster DG \& Alexander RT 2014 Traditional and emerging roles for the SLC9 $\mathrm{Na}+/ \mathrm{H}+$ exchangers. Pflügers Archiv 466 61-76. (https://doi. org/10.1007/s00424-013-1408-8)

Goswami P, Paulino C, Hizlan D, Vonck J, Yildiz O \& Kuhlbrandt W 2011 Structure of the archaeal $\mathrm{Na}+/ \mathrm{H}+$ antiporter $\mathrm{NhaP} 1$ and functional role of transmembrane helix 1. EMBO Journal 30 439-449. (https://doi. org/10.1038/emboj.2010.321)

Jinadasa T, Szabo EZ, Numat M \& Orlowski J 2014 Activation of AMPactivated protein kinase regulates hippocampal neuronal $\mathrm{pH}$ by recruiting $\mathrm{Na}(+) / \mathrm{H}(+)$ exchanger NHE5 to the cell surface. Journal of Biological Chemistry 289 20879-20897. (https://doi.org/10.1074/jbc. M114.555284)

Lee HC \& Garbers DL 1986 Modulation of the voltage-sensitive $\mathrm{Na}+/$ $\mathrm{H}+$ exchange in sea urchin spermatozoa through membrane potential changes induced by the egg peptide speract. Journal of Biological Chemistry 261 16026-16032.
Leung GP, Tse CM, Chew SB \& Wong PY 2001 Expression of multiple Na+/ $\mathrm{H}+$ exchanger isoforms in cultured epithelial cells from rat efferent duct and cauda epididymidis. Biology of Reproduction 64 482-490. (https:// doi.org/10.1095/biolreprod64.2.482)

Lishko PV \& Kirichok Y 2010 The role of Hv1 and CatSper channels in sperm activation. Journal of Physiology 588 4667-4672. (https://doi. org/10.1113/jphysiol.2010.194142)

Liu T, Huang JC, Zuo WL, Lu CL, Chen M, Zhang XS, Li YC, Cai H, Zhou WL, Hu ZY et al. 2010 A novel testis-specific Na+/H+ exchanger is involved in sperm motility and fertility. Frontiers in Bioscience $\mathbf{2}$ 566-581. (https://doi.org/10.2741/e115)

Mannowetz N, Wandernoth P \& Wennemuth G 2012 Basigin interacts with both MCT1 and MCT2 in murine spermatozoa. Journal of Cellular Physiology 227 2154-2162. (https://doi.org/10.1002/jcp.22949)

Martino NA, Ariu F, Bebbere D, Uranio MF, Chirico A, Marzano G, Sardanelli AM, Cardinali A, Minervini F, Bogliolo L et al. 2016 Supplementation with nanomolar concentrations of verbascoside during in vitro maturation improves embryo development by protecting the oocyte against oxidative stress: a large animal model study. Reproductive Toxicology 65 204-211. (https://doi.org/10.1016/j. reprotox.2016.08.004)

Martins AD, Bernardino RL, Neuhaus-Oliveira A, Sousa M, Sa R, Alves MG \& Oliveira PF 2014 Physiology of nat/h+ exchangers in the male reproductive tract: relevance for male fertility. Biology of Reproduction 91 11. (https://doi.org/10.1095/biolreprod.114.118331)

Masereel B, Pochet L \& Laeckmann D 2003 An overview of inhibitors of $\mathrm{Na}(+) / \mathrm{H}(+)$ exchanger. European Journal of Medicinal Chemistry 38 547-554. (https://doi.org/10.1016/S0223-5234(03)00100-4)

Mihaila RG 2015 A minireview on NHE1 inhibitors. A rediscovered hope in oncohematology. Biomedical Papers of the Faculty of Medicine of Palacký University, Olomouc, Czech Republic 159 519-526. (https://doi. org/10.5507/bp.2015.060)

Montrose MH, Friedrich T \& Murer H 1987 Measurements of intracellular $\mathrm{pH}$ in single LLC-PK1 cells: recovery from an acid load via basolateral $\mathrm{Na}+/ \mathrm{H}+$ exchange. Journal of Membrane Biology 97 63-78. (https://doi. org/10.1007/BF01869615)

Mortimer ST \& Maxwell WM 1999 Kinematic definition of ram sperm hyperactivation. Reproduction, Fertility and Development 11 25-30. (https://doi.org/10.1071/RD99019)

Najafi A, Daghigh-Kia H, Dodaran HV, Mehdipour M \& AlvarezRodriguez M 2017 Ethylene glycol, but not DMSO, could replace glycerol inclusion in soybean lecithin-based extenders in ram sperm cryopreservation. Animal Reproduction Science 177 35-41. (https://doi. org/10.1016/j.anireprosci.2016.12.004)

Nejsum LN, Praetorius J \& Nielsen S 2005 NKCC1 and NHE1 are abundantly expressed in the basolateral plasma membrane of secretory coil cells in rat, mouse, and human sweat glands. American Journal of Physiology: Cell Physiology 289 C333-C340. (https://doi.org/10.1152/ ajpcell.00228.2004)

Ng KYB, Mingels R, Morgan H, Macklon N \& Cheong Y 2017 In vivo oxygen, temperature and $\mathrm{pH}$ dynamics in the female reproductive tract and their importance in human conception: a systematic review. Human Reproduction Update 24 15-34. (https://doi.org/10.1093/humupd/ dmx028)

Oberheide K, Puchkov D \& Jentsch TJ 2017 Loss of the $\mathrm{Na}(+) / \mathrm{H}(+)$ exchanger NHE8 causes male infertility in mice by disrupting acrosome formation. Journal of Biological Chemistry 292 10845-10854. (https:// doi.org/10.1074/jbc.M117.784108)

Padan E \& Landau M 2016 Sodium-proton $(\mathrm{Na}(+) / \mathrm{H}(+))$ antiporters: properties and roles in health and disease. Metal lons in Life Sciences $\mathbf{1 6}$ 391-458. (https://doi.org/10.1007/978-3-319-21756-7_12.)

Palacin I, Vicente-Fiel S, Santolaria P \& Yaniz JL 2013 Standardization of CASA sperm motility assessment in ram. Small Ruminant Research $\mathbf{1 1 2}$ 128-135. (https://doi.org/10.1016/j.smallrumres.2012.12.014)

Paoli D, Gallo M, Rizzo F, Baldi E, Francavilla S, Lenzi A, Lombardo F \& Gandini L 2011 Mitochondrial membrane potential profile and its correlation with increasing sperm motility. Fertility and Sterility 95 2315-2319. (https://doi.org/10.1016/j.fertnstert.2011.03.059)

Pedersen SF \& Cala PM 2004 Comparative biology of the ubiquitous $\mathrm{Na}+/$ $\mathrm{H}+$ exchanger, NHE1: lessons from erythrocytes. Journal of Experimental Zoology Part A Comparative Experimental Biology 301 569-578. (https:// doi.org/10.1002/jez.a.47) 
Pereira R, Sa R, Barros A \& Sousa M 2017 Major regulatory mechanisms involved in sperm motility. Asian Journal of Andrology 19 5-14. (https:// doi.org/10.4103/1008-682X.167716)

Perez LJ, Valcarcel A, delas Heras MA, Moses DF \& Baldassarre H 1996 In vitro capacitation and induction of acrosomal exocytosis in ram spermatozoa as assessed by the chlortetracycline assay. Theriogenology 45 1037-1046. (https://doi.org/10.1016/0093-691X(96)00031-3)

Pierri CL, Parisi G \& Porcelli V 2010 Computational approaches for protein function prediction: a combined strategy from multiple sequence alignment to molecular docking-based virtual screening. Biochimica et Biophysica Acta 1804 1695-1712. (https://doi.org/10.1016/j. bbapap.2010.04.008)

Pierri CL, Bossis F, Punzi G, De Grassi A, Cetrone M, Parisi G \& Tricarico D 2016 Molecular modeling of antibodies for the treatment of TNFalpha-related immunological diseases. Pharmacology Research and Perspectives 4 e00197. (https://doi.org/10.1002/prp2.197)

Rimmer SJ 1999 Demonstration of a $\mathrm{Na}(+) / \mathrm{H}(+)$ exchanger $\mathrm{NHE} 1$ in fresh bovine corneal endothelial cell basolateral plasma membrane. Biochimica et Biophysica Acta 1419 283-288. (https://doi.org/10.1016/ S0005-2736(99)00076-0)

RoussaE,AlperSL\&ThevenodF2001 Immunolocalization of anionexchanger AE2, $\mathrm{Na}(+) / \mathrm{H}(+)$ exchangers NHE1 and NHE4, and vacuolar type $\mathrm{H}(+)-$ ATPase in rat pancreas. Journal of Histochemistry and Cytochemistry 49 463-474. (https://doi.org/10.1177/002215540104900406)

Sakkas D, Ramalingam M, Garrido N \& Barratt CL 2015 Sperm selection in natural conception: what can we learn from Mother Nature to improve assisted reproduction outcomes? Human Reproduction Update $\mathbf{2 1}$ 711-726. (https://doi.org/10.1093/humupd/dmv042)

Siyanov V \& Baltz JM 2013 NHE1 is the sodium-hydrogen exchanger active in acute intracellular $\mathrm{pH}$ regulation in preimplantation mouse embryos. Biology of Reproduction 88 157. (https://doi.org/10.1095/ biolreprod.113.109033)

Slepkov ER, Rainey JK, Li X, Liu Y, Cheng FJ, Lindhout DA, Sykes BD \& Fliegel L 2005 Structural and functional characterization of transmembrane segment IV of the NHE1 isoform of the $\mathrm{Na}+/ \mathrm{H}+$ exchanger. Journal of Biological Chemistry 280 17863-17872. (https:// doi.org/10.1074/jbc.M409608200)

Slepkov ER, Rainey JK, Sykes BD \& Fliegel L 2007 Structural and functional analysis of the $\mathrm{Na}+\mathrm{H}+$ exchanger. Biochemical Journal 401 623-633. (https://doi.org/10.1042/BJ20061062)

Sutovsky P, Hewitson L, Simerly C \& Schatten G 1996 Molecular medical approaches for alleviating infertility and understanding assisted reproductive technologies. Proceedings of the Association of American Physicians 108 432-443.

Thomas JA, Buchsbaum RN, Zimniak A \& Racker E 1979 Intracellular $\mathrm{pH}$ measurements in Ehrlich ascites tumor cells utilizing spectroscopic probes generated in situ. Biochemistry 18 2210-2218. (https://doi. org/10.1021/bi00578a012)

Todisco S, Di Noia MA, Onofrio A, Parisi G, Punzi G, Redavid G, De Grassi A \& Pierri CL 2016 Identification of new highly selective inhibitors of the human ADP/ATP carriers by molecular docking and in vitro transport assays. Biochemical Pharmacology 100 112-132. (https:// doi.org/10.1016/j.bcp.2015.11.019)

Wang D, King SM, Quill TA, Doolittle LK \& Garbers DL 2003 A new spermspecific $\mathrm{Na}+/ \mathrm{H}+$ exchanger required for sperm motility and fertility. Nature Cell Biology 5 1117-1122. (https://doi.org/10.1038/ncb1072)

Wang D, Hu J, Bobulescu IA, Quill TA, McLeroy P, Moe OW \& Garbers DL 2007 A sperm-specific $\mathrm{Na}+/ \mathrm{H}+$ exchanger (sNHE) is critical for expression and in vivo bicarbonate regulation of the soluble adenylyl cyclase (sAC). PNAS 104 9325-9330. (https://doi.org/10.1073/pnas.0611296104)

Wohlert D, Kuhlbrandt W \& Yildiz O 2014 Structure and substrate ion binding in the sodium/proton antiporter PaNhaP. Elife 3 e03579. (https:// doi.org/10.7554/eLife.03579)

Woo AL, James PF \& Lingrel JB 2002 Roles of the Na,K-ATPase alpha4 isoform and the $\mathrm{Na}+/ \mathrm{H}+$ exchanger in sperm motility. Molecular Reproduction and Development 62 348-356. (https://doi.org/10.1002/ mrd.90002)

Yang X, Chen J, Bai H, Tao K, Zhou Q, Hou H \& Hu D 2013 Inhibition of $\mathrm{Na}+/ \mathrm{H}+$ exchanger 1 by cariporide reduces burn-induced intestinal barrier breakdown. Burns 39 1557-1564. (https://doi.org/10.1016/j. burns.2013.04.007)

Zhang Z, Yang Y, Wu H, Zhang H, Zhang H, Mao J, Liu D, Zhao L, Lin H, Tang W et al. 2017 Sodium-Hydrogen-Exchanger expression in human sperm and its relationship with semen parameters. Journal of Assisted Reproduction and Genetics 34 795-801. (https://doi.org/10.1007/ s10815-017-0898-2)

Received 25 July 2017

First decision 30 August 2017

Revised manuscript received 21 February 2018

Accepted 27 February 2018 